\title{
Antik Çağ'da Kütüphane Mimarileri: Efes Celcus, Pergamon (Bergama), İskenderiye ve Ninova Örnekleri
}

\section{Library Architectures in The Ancient: Examples of Efes Celcus, Pergamon, Alexanderia and Ninova}

\author{
Burcu Aydemir Şenay ${ }^{1}$ [, Ayşenur Güneş $^{2}$ (1)
}

${ }^{1}$ Araş. Gör. Dr., Atatürk Üniversitesi, Edebiyat Fakültesi, Bilgi ve Belge Yönetimi Bölümü, Erzurum, Türkiye

${ }^{2}$ Araş. Gör. Dr., Kastamonu Üniversitesi, Edebiyat Fakültesi, Bilgi ve Belge Yönetimi Bölümü, Erzurum, Türkiye

ORCID: B.A.Ș. 0000-0003-0409-1571 A.G. $0000-0002-8685-7712$

\section{Sorumlu yazar/Corresponding author:} Burcu Aydemir Şenay,

Atatürk Üniversitesi, Edebiyat Fakültesi, Bilgi ve Belge Yönetimi Bölümü, Erzurum, Türkiye E-posta: burcua04@gmail.com

Başvuru/Submitted: 25.05 .2021 Revizyon Talebi/Revision Requested: 08.06.2021 Kabul/Accepted: 20.06.2021

Online Yayı/Published Online: 25.06.2021

Atıf/Citation: Aydemir Şenay, B ve Güneș, A. (2021). Antik Çağ'da kütüphane mimarileri: Efes Celcus, Pergamon (Bergama), İskenderiye ve Ninova örnekleri. Bilgi ve Belge Araştırmalart Dergisi, 15, 95-107.

http://doi.org/10.26650/bba.2021.15.05

\section{Öz}

Kütüphaneler, kuruldukları günden günümüze kadar farklı unsurlar bağlamında sürekli bir değişim içerisindedir. Bu değişim, bazen sunulan hizmetler yönünden değerlendirilebildiği gibi bazen de mekânsal farklılık ve değişim olarak değerlendirilmektedir. Kütüphaneler tıpkı diğer bilgi merkezleri gibi bulundukları dönem, toplum ve o günün inşa tekniklerine bağlı olarak günümüzde de değişmeyen ana amaç olan bireylerin bilgi gereksinimlerini karşılama amacıyla oluşturulmuşlardır. Kuşkusuz fiziksel mekânlarda mimari olarak çekicilik, iç mimariye bağlı olarak kaynaklara erişim kolaylığı vb. gibi etmenler ile bireylerin ve toplumların kütüphane kullanımları ve alışkanlık edinimleri arasında doğru orantı vardır. Günümüzde, kütüphane mimari yapısının hangi etmenler üzerinden değerlendirilerek inşa edilmesi gerektiğine yönelik yaklaşımlar, araştırmalar ve çeşitli çalışmalar yapılmaktadır. Bu çalışma kapsamında bulundukları döneme mimari yapılarıyla da damga vuran Efes Celsus, Pergamon, İskenderiye ve Ninova Kütüphanelerinin değerlendirilmesi amaçlanmıştır. Bu bağlamda çalışmada, belgesel tarama yöntemi kullanılarak literatürde bulunan kaynaklar ayrıntılı araştırılmış, bu kaynaklar çalışmada ilgili bulunan bölümlerde değerlendirilmiştir.

Anahtar kelimeler: Kütüphane, Kütüphane mimarisi, Antik kütüphaneler

\section{ABSTRACT}

Libraries have been in a constant state of change in the context of different elements since they were founded. This change can be evaluated in terms of the services provided and sometimes as spatial difference and changes. Libraries, just like other information centers, have been created to meet the information needs of individuals and this main purpose has not changed over time but reflects the period they are in, the society and the construction techniques of the day. Undoubtedly, there is an architectural attraction in physical spaces, allowing ease of access to resources depending on interior architecture. Library usage is in direct proportion to the habits of acquisition of individuals and the wider society. Various researches and studies have been carried out to appraise the structural features of the library's architecture by evaluating relevant factors. The aim of the study here is to evaluate the libraries of Ephesus Celsus, Pergamon, Alexandria and Nineveh which were remarkable for their period with their architectural structures. For the purpose of this study, the sources in the literature were investigated in detail using the documentary screening method and were evaluated in relevant sections of the study.

Keywords: Library, Library architecture, Ancient libraries 


\section{EXTENDED ABSTRACT}

There are many definitions and approaches in the literature regarding the concept of design. With the most general approaches, design is defined in terms of thinking, problem-solving, decision-making, a trial-and-error process. According to the broadest definition found in the literature, design is a way of visualizing, shaping and/or producing any plan and/or sketch. Thought processes, which are the basis of the design, turn into a design depending on the creative ability of the individuals and the limits of creativity. These products have had an impact on societies from the past to the present. At this point, architectural design is considered a creative cognitive process. Sharing and storing the information produced is one of the basic needs of individuals in every period across history. The process of sharing and storing information, starting with text on papyrus, continues with the information resources available in electronic media today. The main environment that allows this sharing is undoubtedly a library. It should not be forgotten that the basic elements of libraries as an information center are the building's architecture, budget, staff, and the collection of literature housed within them. The attractive and admirable nature of library buildings is their undoubtedly important factors that affect their usage. Apart from this, designing a new library building and/or the reorganization of an existing building is carried out in the context of various factors. Factors such as functionality, ease of access, high user interaction, safety, and simplicity are important factors to be considered during the design phase. Throughout history, individuals' thought processes can be clearly traced in the architectural design phase of these buildings; further, the resulting structures also affect the society they are in. It is possible to observe the effects of the culture and period in which they were found, especially in the structures that emerged in the ancient period. However, such structures belonging to the ancient period still carry the traces of the civilization in which they were located. Library buildings in Alexandria, Ephesus Celsus, Nineveh, and Pergamon are among the most important examples. The library of Alexandria was one of the most important architectural structures created, with its unique architecture, it was the largest archive in the world for 300 years and contained 150.000 manuscripts. The Ephesus Celsus library was a magnificent structure built within the borders in Turkey. It hosted approximately 14.000 resources, and it is known that book rolls were kept in niches inside the walls. The Pergamon library rivaled other important libraries of the period with approximately 200.000 manuscripts, both papyrus and parchment codices, and a unique architectural style. The Nineveh library was similar to the Pergamon library. Nineveh was one of the most important structures when evaluated in terms of architectural features, and being the first known library in the world with its collection of approximately 30.000 engraved tablets. These libraries, which served humanity and science for centuries, stand out due to their geographic locations and their role in scientific advancement. There are differences between these libraries in the types of materials that was used to record information and the way they were utilized. They continue to carry the traces of ancient civilizations to the present. 


\section{GİRIŞ}

Kütüphaneler, geçmişten günümüze bireylerin bilgi gereksinimlerinin karşılanması amacıyla bilgi kaynakları arasında ilişki kurulmasına olanak tanıyarak bu amaca yönelik bilgi kaynaklarının seçimi, sağlanması, düzenlenmesi ve kullanıcıların erişimine sunulması vb. gibi hizmetleri sunan kuruluşlardır. Bu nedenle kütüphaneler, bilim, kültür, eğitim ve sanat yaşamının vazgeçilmez mekânları olmuşlardır (Üreten, 2008, s. 435). Kütüphaneler, teknolojinin gelişimi, bireylerin düşünce yapısındaki meydana gelen değişimler, bilgiye duyulan gereksinim vb. gibi nedenlerle yüzyıllar içerisinde farklı şekillerde inşa edilmişlerdir. Özellikle kütüphanelerin içerisinde kullanılan kaynakların türleri, kütüphanelerin yapılarında da etkili olmuştur. İlk kütüphane türleri, kitapları kullanmaktan çok depolayıp saklamayı görev edinmiştir (Keseroğlu, 2010, s. 47). Bu nedenle, antik dönemdeki kütüphanelerin aslında arşiv olarak isimlendirilmesi mümkündür. İlk yazılı belgelerle başlayan bilgi aktarımı sürecinin en temel taşı olan kütüphaneler, tarih boyunca bulundukları coğrafyanın, dönemin ve uygarlıkların belleğini oluşturarak gelecek kuşaklara iletme görevini üstlenmişlerdir.

\section{Kütüphane Mimarileri ve Gelişim Süreçleri}

Tarih boyunca kütüphane mimarileri açısından farklı yapılarla karşılaşılmaktadır. Bunlardan bazıları yapı olarak günümüze kadar gelebilmişken bazıları ise yapı olarak ayakta kalamamıştır. Buna rağmen dönemin ihtişamlı yapıları olmasından ötürü kendilerinden söz ettirerek, etkilerini günümüze kadar taşımışlardır. Özellikle Yakındoğu kültürlerinde belgelerin toplanması, korunması ve saklanması amacıyla kütüphane ve/veya arşiv yapıları oluşturulmuştur (Sonay, 2019, s. 21). Mezopotamya coğrafyasında ise kültürel birikimin yazıya ve metne bağlı şekilde gelişiminde rol oynayan "tapınak evlerinin” oluştuğu, Mısır' da yine aynı düşünce altında yaşam evlerinin oluştuğu bilinmektedir. Bu bağlamda kütüphane ve/veya arşiv yapıları oluşmaya ve gelişmeye başlamıştır (Assman, 2001'den aktaran Toplu, 2010, s. 651).

Bir kütüphanenin mimari olarak değerlendirilebilmesi, farklı özel bir yapıda hizmet vermesiyle ve/veya herhangi bir yapıda kütüphane ve/veya arşiv hizmeti sunulabilecek bir bölüm/oda/kat bulunmasıyla mümkündür (Blanck, 2000, s. 199). Kütüphane koleksiyonlarına bağlı olarak düzenli kayıtların oluşması ve bu kayıtların depolanmaya başlamasıyla çok katlı kütüphane yapıları inşa edilmeye başlanmıştır (Fleming ve Honour, 2016, s. 40). Antik dönemde kütüphane yapılarının yan duvarlarına dekoratif amaçlı nişlerin ${ }^{1}$ yapıldı̆̆ 1 , bu nişlerin ise kitap rulolarının yerleştirilmesi bakımından çok önemli olduğu bilinmektedir. Aynı zamanda kütüphane binasının girişinin karşısında yer alan büyük nişlere kütüphaneyi koruduğuna inanılan tanrıların ya da bilim adamlarının heykelleri yerleştirilmektedir (Yıldız, 2003, s. 357).

1 Niş: "Duvar içinde bırakılan oyuk" (TDK, 2021). 
Kazılar sonucunda kütüphane binalarında yer alan nişler sayesinde kazı gerçekleştirilen bölgede kütüphane yapısı olup olmadığı anlaşılmaktadır. Ayrıca süsleme amacıyla yapılan küçük nişler kütüphanelere verilen değeri göstermektedir. Bir başka ifadeyle kütüphaneler sadece kitap deposu olarak görülmemiş aynı zamanda yaşam alanı olarak değerlendirilmişstir. Kütüphaneler içerisinde yer alan tanrı heykelleri ise yine kütüphanelerin sosyal hayat ile bir bütün olduğunun göstergesidir. Arkeolojik kazılar sonucunda kütüphanelerin büyük çoğunluğunun gün 1şığından faydalanmak amacıyla doğuya baktığı sonucuna ulaşılmıştır (Yıldız, 2003, s. 372). Bu durum kütüphanelerin aydınlatılmasında gün ışığı kullanıldığını göstermekle birlikte kütüphane binalarının bir yapı içerisinde bulunsa dahi doğu yönüne bakmasına önem verildiğini ortaya koymaktadır.

19. yüzyıla kadar kütüphaneler ile müzelerin aynı yapı içerisinde hizmet verdikleri görülmektedir. Ayrıca 19. yüzyılda dökme demir konstrüksiyon, ${ }^{2}$ nem, 1 sı ve havalandırmanın çok yönlü denetimi ile kitap stoklarının güvenliği iyileştirilmeleri yönünde gelişmeler olmuştur. 1930'larda ise modern kütüphanecilik anlayışı gelişmiş ve kitap rafları ile okuma salonu ayrımı ortadan kalkarak aynı yerde akıcı hizmet verilmesi anlayışı doğmuştur. İşlevsellik, esneklik ve rahatlık ön plana çıkmıştır (Tercan, 2010, s. 40). Modern anlayışla birlikte kütüphanelerin tasarımında, kullanıcı odaklı olması ön planda tutulmuştur. Böylece kütüphaneler kamusal alanlara dönüşmüş ve sosyalleşme sağlanmıştır. Kütüphanelerin değişim süreci, kitap depolama ve kullanım düzenlemelerindeki değişiklikler, aşağıda sunulan Tablo 1'de daha detaylı bir şekilde belirtilmiştir.

Tablo 1. Kütüphanelerin kitap depolama ve kullanım düzenlemelerindeki değişiklikler (Edwards, 2009, s. 7).

\begin{tabular}{|c|c|c|c|c|c|}
\hline Tip & Materyal & Tarih & Okuma düzeni & $\begin{array}{c}\text { Mekân } \\
\text { biçimleri }\end{array}$ & Tipik örnekler \\
\hline $\begin{array}{l}\text { Birleşik sistem; } \\
\text { kütüphane ve müze }\end{array}$ & Papirüs tomarı & Antik Çağ & Ayakta & Kubbe ile açılmış & $\begin{array}{c}\text { İskenderiye } \\
\text { Kütüphanesi, } \\
\text { Misır } \\
\end{array}$ \\
\hline $\begin{array}{l}\text { Avlu sistemi; } \\
\text { kitap rafları ile } \\
\text { oluşturulmuş }\end{array}$ & Dini kitaplar & 6.-13. yüzyı1 & Oturarak & Açık avlu & $\begin{array}{l}\text { Tintern Abbey, } \\
\text { Monmouthshire }\end{array}$ \\
\hline $\begin{array}{l}\text { Avlu sistemi; } \\
\text { kitap rafları ile } \\
\text { oluşturulmuş }\end{array}$ & $\begin{array}{c}\text { El yazıs1 } \\
\text { kitaplar, basıl1 } \\
\text { kitaplar } \\
\end{array}$ & 13.-16. yüzy1l & Ayakta & Doğrusal ve dar & $\begin{array}{c}\text { Leyden } \\
\text { Üniversitesi, } \\
\text { Hollanda } \\
\end{array}$ \\
\hline $\begin{array}{l}\text { Tezgah sistemi; raf } \\
\text { ve oturma bölmeleri } \\
\text { birleştirilmiş }\end{array}$ & Basılı kitaplar & 16.-17. yüzyıl & Oturarak & Doğrusal & $\begin{array}{c}\text { Laurenziana } \\
\text { Kütüphanesi, } \\
\text { Floransa İtalya }\end{array}$ \\
\hline $\begin{array}{l}\text { Duvar sistemi; } \\
\text { kitap raflarıyla } \\
\text { çevrili }\end{array}$ & Bas1lı kitaplar & 17.-18. yüzyı1 & Oturarak & $\begin{array}{l}\text { Dairesel ve } \\
\text { dikdörtgen }\end{array}$ & $\begin{array}{c}\text { Bodleian } \\
\text { Kütüphanesi, } \\
\text { Oxford İngiltere }\end{array}$ \\
\hline
\end{tabular}

2 Konstrüksiyon: "Yapı, yapım" (TDK, 2021). 


\begin{tabular}{|l|c|c|c|c|c|}
\hline $\begin{array}{l}\text { Okuma odalı } \\
\text { sistem; kitap } \\
\text { galerili }\end{array}$ & $\begin{array}{c}\text { Basılı kitaplar, } \\
\text { haritalar ve } \\
\text { dergiler }\end{array}$ & 16.-20. yüzyıl & Oturarak & $\begin{array}{c}\text { Açık merkez } \\
\text { planı çevresi } \\
\text { odalarla } \\
\text { kapatılmış }\end{array}$ & $\begin{array}{c}\text { Ulusal } \\
\text { Kütüphane, } \\
\text { Paris, Fransa }\end{array}$ \\
\hline $\begin{array}{l}\text { Açık plan sistemi; } \\
\text { bilgisayar ve açık } \\
\text { kitap raflarıyla } \\
\text { entegre }\end{array}$ & $\begin{array}{c}\text { Basılı yayınlar, } \\
\text { CD-ROM'lar } \\
\text { ve diğer dijital } \\
\text { bilgi sistemleri }\end{array}$ & $\begin{array}{c}\text { 20. yüzyıl ve } \\
\text { sonrası }\end{array}$ & Oturarak & Geniş, açık plan & $\begin{array}{c}\text { Kütüphanesi, } \\
\text { Cambridge } \\
\text { Üniversitesi }\end{array}$ \\
\hline
\end{tabular}

Tablo 1'de kütüphanelerin yüzyıllar içerisinde değişimi, mekân ve kullanım düzenlemeleri bağlamında tablo, plan ve kesit çerçevesinde değerlendirilmiştir.

\section{Antik Çağ'ın Kütüphaneleri}

Aşağıda kütüphanelerin sadece kaynaklarıyla, hizmetleriyle, araştırmacılarıyla değil aynı zamanda mekân tasarımı ve mimari özellikleri açısından da büyük öneme sahip olan dört Antik Çağ kütüphanesi ele alınarak değerlendirilmiştir.

\subsection{Efes Celcus Kütüphanesi}

Efes antik kenti, Roma ve Bizans medeniyetlerinin izlerini taşıyan, önemli bir kültür ve sanat merkezi olarak bilinmektedir. Asya'nın en büyük ve ilk metropolü olma özelliği ile birlikte Roma İmparatorluğu zamanında oldukça parlak bir dönem geçirmiştir. Efes Celcus Kütüphanesi ise Hellenistik Agora'nın güney kapısı yanında 1903-1905 yılları arasında R. Heberdey ve O. Bendorf tarafından gerçekleştirilen kazılar sonucu ortaya çıkmıştır. 1970-1978

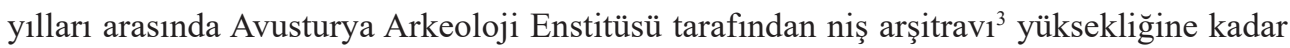
restore edilmiştir (Yıldız, 2003, s. 227). Kütüphane girişinde yer alan yazıtta,

Asia proconsul'u Tiberius Iulius Celcus Polemaeanus için, oğlu Concul Tiberius Iulius Celcus Polemaeanus kendi serveti ile Celcus kütüphane binasını, bütün dekorasyonu, sanat eserleri ve kitapları ile birlikte kurdu. Kütüphanenin korunması ve kitap alınması için 25.000 denarion'u onun için bir başlangıç olmak üzere miras bıraktı. Aquila'nın mirasçıları onu tamamladılar ve vasiyete uygun olarak, bu yapı üç kez Asiarkhos olan Tiberius Claudius Aristion tarafindan adandi.

ifadesi yer almaktadır. Bu yazıtla birlikte kütüphanenin kim tarafından ne şekilde yaptırılmış olduğu anlaşılmaktadır. Kütüphanenin M.S. 113-117 yıllar arasında yapımına başlandığı ve M.S. 135 yılında ise tamamlandığı düşünülmektedir (Yıldız, 2003, s. 228).

3 Arşitrav: Klasik yapılarda bir saçaklık veya kirişin üç bölümünden en küçük olanı (Ambrose, Harris ve Stone, 2008, s. 45). 


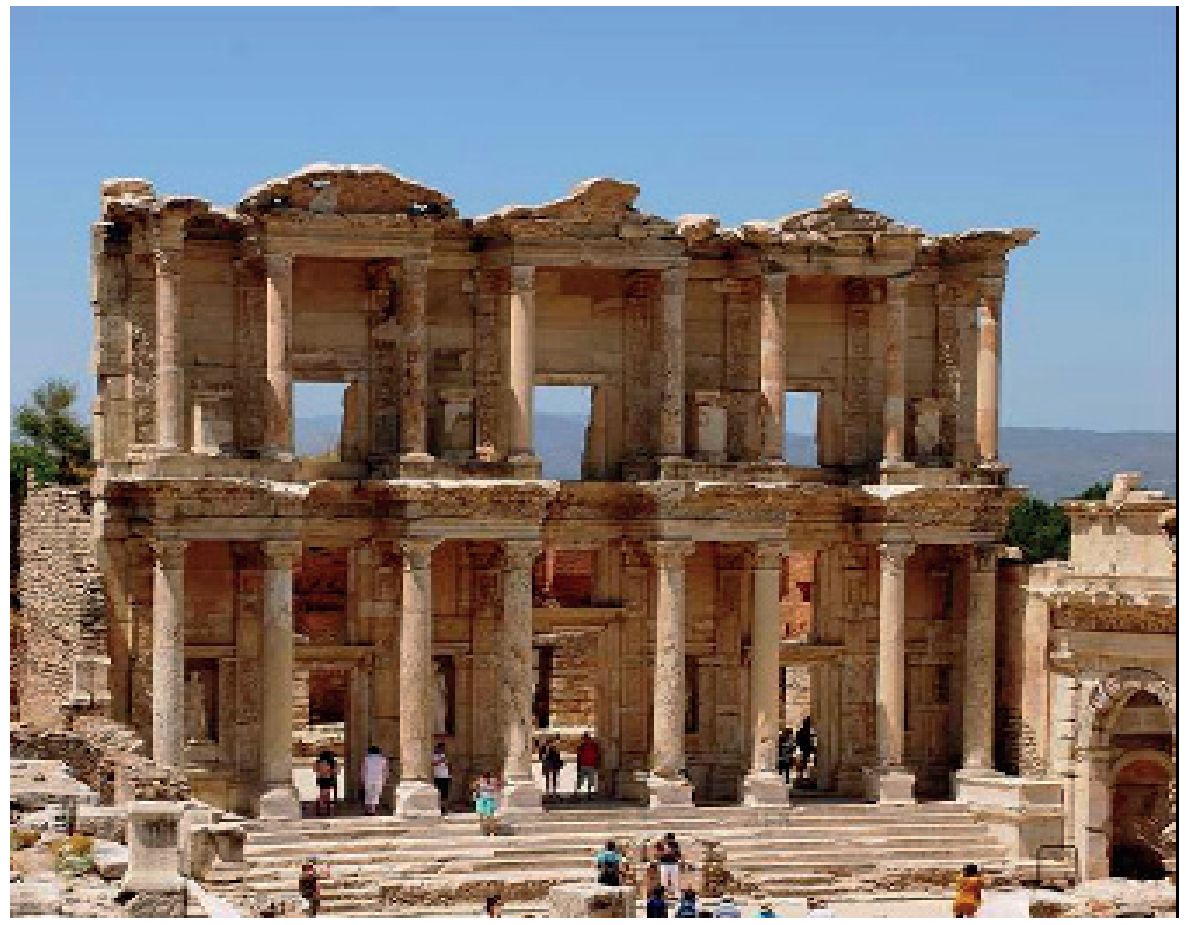

Resim 1. Efes Celsus Kütüphanesi (Kültür ve Turizm Bakanlığı, 2021)

150 yıl hizmet verdikten sonra M.S. 262 yılında çıkan Got yağmaları ile kütüphanenin tahrip edildiği bilinmektedir. Bu yağmalar sonucunda Resim 1'de de görülen kütüphanenin ön cephesi sağlam kalabilmiştir (Taşkın, 2011, s. 94). Bilim adamlarının, şairlerin ve hatiplerin konferans verdiği oditoryum'a ${ }^{4}$ yakın olması kütüphanenin önemini artırmaktadır. Dış cephesinde, sütun dekorasyonu iki katı kaplamış şekildedir. İlk katta sekiz sütun yer almaktadır. Sütunlar arasında yer alan üç kapı ile kütüphanenin salonuna girilmektedir. Kapıların üzerinde 1şığı sağlayan süslü pencereler bulunmaktadır. Kapıların yan taraflarında bulunan payelerin yanında nişler yer almakta, bunların üzerinde elbiseli heykeller bulunmaktadır. Bu heykeller, Celcus'un Bilim, Akıl, Erdem ve Kaderi temsil eden dört kadın heykelden oluşmaktadır (Yıldız, 2003, s. 232). Kütüphane içerisinde yer alan niş boşluklarına kitap dolapları oturtulmuştur. Diğer kütüphane örneklerinde yer aldığı gibi içerisinde sütunlu bir hol bulunmamaktadır. Basamaklı merdivenler ile podium (sütun tabanı) üzerine oturtulmuş bir yapısı vardır.

Kütüphaneye üç kapıdan girildiğinde, batı duvarının karşısında yer alan apsis'in (yarım kubbe) içerisinde bir heykel olduğu bilinmektedir. Ancak heykel'in Bergama Kütüphanesinde olduğu gibi Athena'ya mı yoksa Celcus'a mı ait olduğu bilinmemektedir (Gül, 1998, s. 101).

4 Auditorium: “Antik Roma'da halkın ozanları dinlemek üzere toplandiğl yer” (TDK, 2021). 
Apsis'in yer aldığ 1 duvar dışındaki duvarlar çift duvardan oluşmaktadır. İki duvar arasında $120 \mathrm{~cm}$ genişliğinde bir koridor bulunmaktadır. Bu koridorun yangın durumunda kitapları, çekmeceleri, parşömen ve papirüsleri korumak amacıyla yapıldığı düşünülmektedir. İç duvarların üç tarafında içine kitapların konulduğu dikdörtgen şeklinde on adet niş bulunmaktadır. Nişlerin bulunduğu duvarların alt kısmında podiumlar yer almaktadır.

Bu podiumlarla ilgili iki görüş bulunmaktadır:

- Okuyucuların direk olarak kitaba ulaşmasını engellemek,

- $\quad$ Estetik olarak güzel görünmesi (Y1ldız, 2003, s. 240-241).

Kütüphanenin aydınlanmasına yönelik iki görüş bulunmaktadır. Bunlardan ilki kütüphanenin, çatıda bulunan merkezi bir açıklıktan aydınlanması, ikincisi ise kapı ve pencerelerden gelen ışıkla aydınlandığı yönündedir.

\subsection{Pergamon (Bergama) Kütüphanesi}

Pergamon şehri, Makedon İmparatorluğu'nun dağılmasının ardından, Attalos Hanedanlığı yönetimine geçmiştir. Attalos Hanedanlığı'nın başına ilk olarak I. Attalos geçmiştir. I. Attalos; sanat ve kültüre düşkün yapısı bulunduğundan, şehri güzel mimari yapılar ile donattı̆̆ bilinmektedir. I. Attalos'un ardından II. Eumenes yönetimine geçen Pergamon önemli kültür merkezlerinden biri olmuştur. Pergomon kütüphanesinin yapılması konusunda net bir bilgi olmasa da birçok kaynakta, I. Attalos zamanında yapımına başlandığı, II. Eumenes zamanında ise kullanıma açıldığı yönünde bilgiler bulunmaktadır. M.Ö. 241-197 yılları arasında yapımına başlandığı düşünülen Pergamon Kütüphanesi, M.Ö. 197-159 yılları arasında en parlak dönemini yaşamıştır (Gül, 1998, s. 97). Pergamon Kütüphanesinin, antik çağ döneminde İskenderiye Kütüphanesinden sonra en büyük ve en zengin koleksiyona sahip kütüphane olduğu bilinmektedir. İskenderiye Kütüphanesinden yaklaşık yarım asır sonra kurulan kütüphane, en önemli özelliğini İskenderiye Kütüphanesine benzemekten almaktadır (Tunay, 1970, s. 110).

O dönem, Pergamon Kütüphanesini büyütmek adına yeni eserlerin yazılmaya başlandığg, eski eserlerin ise satın alma yoluyla edinildiği bilinmektedir. Bütün bu çalışmalar, Pergamon Kütüphanesini İskenderiye Kütüphanesi ile rekabet edecek konuma getirmiş, bunun üzerine Mısır kralı Ptolemaios Epiphanes papirüs ihracını yasaklamıştır. Bu nedenle Sardes'li Krates ise keçi derisinden özel bir kağıt imal ettirmeyi düşünmüş ve bu kağıda da "Pergamnae Charte" (Bergama Kağıdı) denilmiştir. Pergament adını alan bu kâğıt daha sonra koyun ve kuzu derisinden de imal edilmeye başlanmıştır. Pergamentin papirüsten daha kullanışlı olduğu ve daha uzun yıllar sağlam kalabileceği düşüncesiyle, tercih edilmeye başlandığı bilinmektedir. Ayrıca papirüsün sadece rulo şeklinde kullanılabiliyor oluşu; buna karşın pergamentin ciltlenebilmesi de kullanımını arttıran bir diğer neden olduğu düşünülmektedir(Yıldız, 2003, s. 140). Pergamon 
Kütüphanesinin tarihte önemli olmasının nedeni, İskenderiye Kütüphanesi ile rekabet edecek konumda olması ve bu rekabet sonucunda parşömenin bulunmuş olmasıdır. Ayrıca Pergamon Kütüphanesi, kataloglama çalışmaları başta olmak üzere kütüphanecilik çalışmalarının yapıldığı ilk kütüphane olması açısından da önemli olarak görülmektedir. Parşomenin bulunması ile birlikte kütüphane, ilk kez kitapların yan yana dizildiği yer olması açısından önemlidir (Keseroğlu, 2010, s. 48).

Pergamon Kütüphanesinin yeri, 1884 yılında iki Alman arkeolog tarafından gerçekleştirilen kazı çalışmasında belirlenmiştir. Söz konusu kazıda, Athena Mabedi'nin arkasında bulunan dört odanın kütüphane olarak yapılaştırıldığı düşünülmüştür. Daha sonra yapılan kazılarda ise mabedin yanında bulunan saraylarda herhangi bir kütüphane yapısına benzer bir yapının bulunamayışı, ilk yapılan kazıdaki kütüphane düşüncesini netleştirmiştir (Tunay, 1970, s. 110).

Kazılarda bulunan dört odadan birinin geniş olduğu ve bu en geniş odanın esas kütüphane olduğu diğer üç odada ise duvarlarda kaide ve oyuklara rastlanmamasından depo olarak kullanıldığı düşünülmektedir. Söz konusu dört oda birbirinden bağımsız olmamakla birlikte sütunlu avlular ile birbirine bağlı konumdadır. Esas kütüphane olarak düşünülen oda, doğu yönünde bulunan ilk odadır. Bu odanın duvarlarına düzenli aralıklarla oyuklar yer almaktadır. Duvarların önünde ise podiumlar yer almaktadır. Bu podiumlar ve kitap rafları konusunda birçok görüş ön plana çıkmaktadır. Bu görüşlerin bir kısmı, podiumların kitap rafları olarak kullanıldığını savunmaktadır, diğer bir kısmı ise podiumlarda kitap olmadığı aksine podiumların kullanıcılar ile kitaplar arasında engel olduğunu ve kullanıcıların kitaplara doğrudan erişiminin engellendiğini savunmaktadır. Pergamon Kütüphanesi ile ilgili bir başka görüş ise kütüphane olarak düşünülen bu büyük odada Bergama bilginlerinin akademik toplantılar yaptığı görüşüdür. Bu nedenle söz konusu oda, şeref salonu olarak nitelendirmiştir. Pergamon Kütüphanesinin bu büyük salonunun 12.500 kadar rulo barındırabilecek boyutta olduğu düşünülmektedir. Depo olarak düşünülen diğer odaların ise 800 civarında rulo barındırabileceği düşünülmektedir (Üreten, 2008, s. 446).

Pergamon Kütüphanesinin ana yapısının yokuşlu bir arazi üzerinde bulunduğu, arazinin bu yapısından kaynaklı olarak kütüphaneye üst katlardan da girilebildiği düşünülmektedir. Kütüphanede yer alan pencereler, salonun doğu ve batı yan duvarlarında, üst kısma yakın yerde bulunmaktadırlar. Hellenistik tarzda kesme taşlardan oluşan duvarlar kenetlerle birbirlerine bağlanmış durumdadır. Kütüphanede bulunan odaların tamamının Stoa'ya ${ }^{5}$ açıldığı; bununla birlikte kütüphane binasının Stoa' dan önce yapıldığı bilinmektedir. Diğer Antik Çağ yapılarında Stoa ve odalar arasında bağlantı varken Pergamon Kütüphanesinde bu bağlantı gerekli yapı kurallarına uygun değildir. Aynı zamanda kütüphane çatısının tahtadan yapıldığı yer döşemesinin

5 Stoa, "ilk ortaya çıktığında iki kısa ve bir uzun kenarı kapalı diğer uzun kenarı açık olan en basit örneğinde eğilimli veya düz olan çatısı bir sıra sütunla taşıyan uzun ve tek katlı yapılan" (Ersoy, 2015, s. 51) sütunlu galerilerdir. 
ise mozaik taşlardan yapıldığına dair bulgular çeşitli arkeolojik kazılarda ortaya çıkarılmıştır (Tunay, 1970, s. 111). Kütüphanenin aydınlatılabilmesi amacıyla pencerelerin kuzey Stoa tarafında bulunan giriş duvarında olduğu, doğu ve batı duvarlarında da ek pencereler olduğu, bu sayede güneşin hareketine göre sürekli olarak kütüphanenin aydınlık kalacak şekilde pencerelerin uygun yerlere konumlandırıldığı düşünülmektedir.

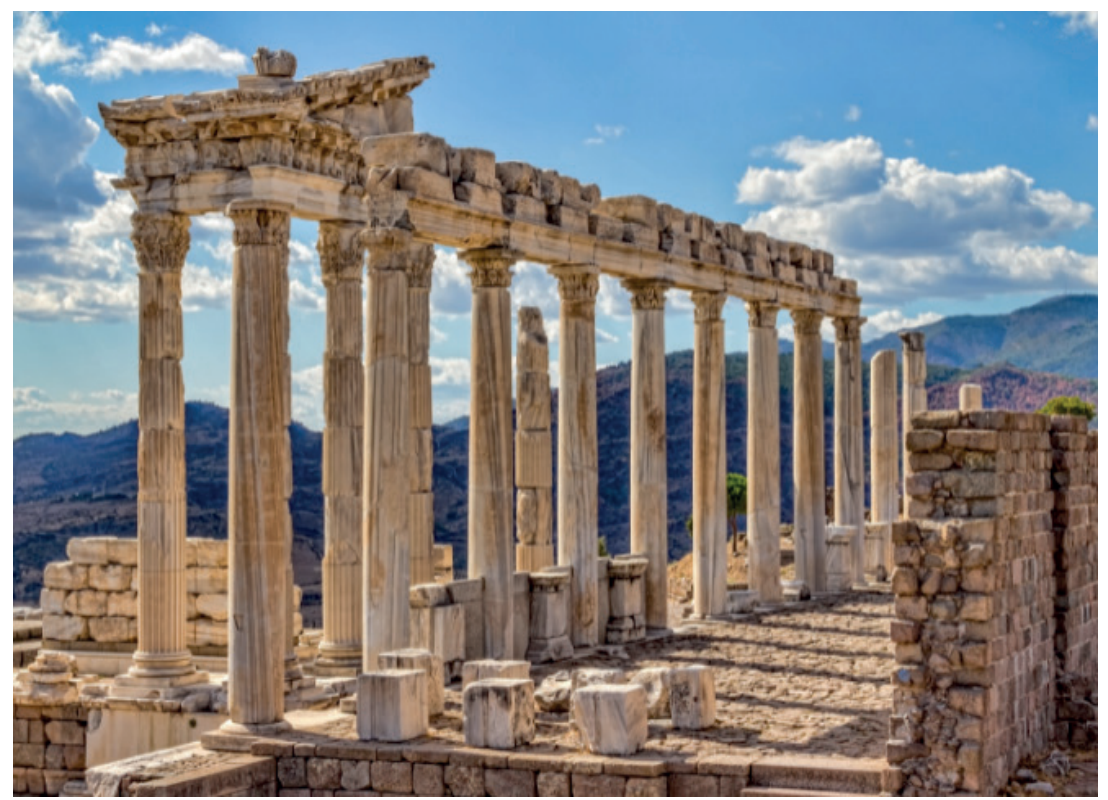

Resim 2. Pergamon (Bergama) Kütüphanesi (Britannica, 2021)

Pergamon Kütüphanesinin batı duvarında şehrin koruyucu tanrıçası olan Athena'nın heykeli bulunduğu, ayrıca yazarların, şairlerin, düşünür ve sanatkarların heykellerinin konulması geleneğinin ilk olarak Pergamon Kütüphanesinde başlatıldığı bilinmektedir. Homeros, Heredotos, Sappho, Timotheos, Balkaras, ve Appollonios heykellerinin yanı sıra parşömen mucitleri Krates ve İrodikos'un heykelleri de kütüphanede yer almaktadır (Gül, 1998, s. 99).

\section{3. İskenderiye Kütüphanesi}

İskenderiye Kütüphanesi, Aristoteles'in Lykeion'da bulunan kütüphanesi örnek alınarak kurulmuştur. İskenderiye kentinin Brukheion mahallesinde, krallık akademisinde kurulan İskenderiye Kütüphanesinin eski hali ve planı belirlenememiştir. (Yıldız, 2003, s. 64). Kütüphanede 500.000 kadar rulo olduğu düşünülmektedir. İskenderiye Kütüphanesinin yapısına dair çok fazla bilgi edinilememiştir. Ancak, arkeologların buldukları kalıntılardan çıkardıkları yorumlar ile tahminde bulunulmaktadır. İskenderiye'de kurulan kütüphane aynı zamanda dünyada ilk müze-kütüphane olması açısından önemlidir (Gül, 1998, s. 96). Antik 
dönemde yer alan birçok kütüphane örneğinde görüldüğü gibi müze ve kütüphane iç içedir. Kütüphanenin müzenin yanında yer aldığı ve kütüphane içerisinde üstü kapalı geçitler boyunca siralanan rafların olduğu bilinmektedir (Macleod, 2006, s. 17). İskenderiye Kütüphanesine ait görsel Resim 3'te sunulmuştur.

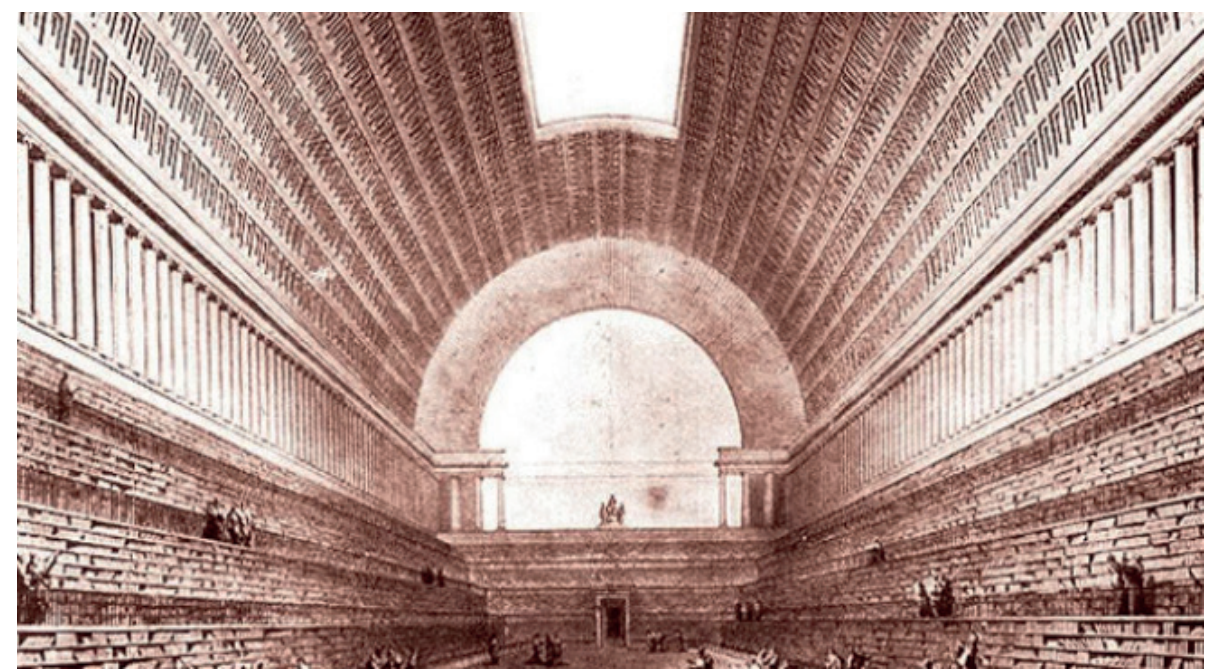

Resim 3. İskenderiye Kütüphanesi (TRT, 2021)

Araştırmacıların görüşlerine göre; kralın sarayında bol ağaçlıklı, en güzel yerde bulunan bir bölümü müze- kütüphane oluşturmaktadır. O dönemde bu bölümün daha çok bir akademi olarak değerlendirildiği bilinmektedir. Bu bölümde ayrıca öğrencilerin toplantılar yaptığı, tartıştıkları konferans salonları bulunmaktadır. Krallığın içerisinde yer alan bu kütüphanede kitap sayısı arttıkça Serapium' da ${ }^{6}$ ek bir kütüphane oluşturulmuştur (Gül, 1998, s. 97). Burada kütüphanedeki kaynakların sayısının ne kadar fazla olduğu ve kullanımının ne derece önemli olduğu yorumu yapılabilir.

İskenderiye Kütüphanesinde kullanılan papirüslerin depolama şekli kil tabletlerden farklı olduğundan, bu özelliği mimari yapılarına yansıtmıştır (Keseroğlu, 2010, s. 48). Rulolar, kütüphane duvarlarında yer alan nişler içerisinde saklanmaktadır. İskenderiye Kütüphanesinde depo odalarının bir Oikos'a bağlı olduğu, bilginlerin gezinti yerlerinin ve ortaklaşa yemek yedikleri bir salonun olduğu bilinmektedir (Yıldız, 2003, s. 353). Eski yunan kütüphanelerinde, en büyük ve ünlü kataloğun Kallimakhos tarafindan İskenderiye Kütüphanesi için hazırlandığı (Yıldız, 2003, s. 329) bilinmektedir. Bu durum İskenderiye Kütüphanesinin kütüphanecilik açısından önemi de ortaya çıkarmaktadır. İskenderiye

6 Serapium, Eski Mısır'ın iki tapınă̆ından biri olup, Sarapeum veya Sarapieion olarak da ifade edilmektedir (Britanicca, 2021). 
Kütüphanesinin yeni yapısının ise eski kütüphanenin bulunduğu bölgede hemen hemen aynı konuma yerleştirildiği bilinmektedir.

\subsection{Ninova Sarayı Kütüphanesi}

Ninova Kütüphanesi, Assurbanipal'in kütüphanesi olarak bilinmektedir. Assurbanipal'in kütüphanesini 1850 yılı civarında İngiliz arkeolog Layara ve Rassam Ninova'da Musul yakınlarında ortaya çıkarmıştır. Kütüphanenin kuruluş zamanı tam olarak bilinmemekle birlikte Assurbanipal'in M.Ö. 669-626 yıllarında yaşadığı ve kütüphanenin M.Ö. 8. yüzyılda II. Sargon zamanında var olduğu bilinmektedir (Gül, 1998, s. 94). Menant (2005, s. 103), bu kütüphanenin günümüze kadar ulaşan en eski kitap deposu olduğu görüşündedir. Ninova Sarayı Kütüphanesinin, Anadolu'da kurulan ilk kütüphane örneği olduğuna yönelik birçok kaynakta görüş bulunmaktadır.

Ninova Kütüphanesi koleksiyonun yaklaşık olarak 30.000 tabletten oluştuğu düşünülmektedir (Yıldız, 2003, s. 14). Yazı malzemesi olarak tabletlerin ve çivi yazısının kullanılması sebebiyle, kütüphanenin iç düzenlemesinin diğer kütüphanelere göre farklı olduğu düşünülmektedir. Layard, gerçekleştirmiş olduğu kazıda birbirine bağlı iki oda bulunduğunu belirlemiştir. Aynı zamanda bu odaların içinin kil tablet ile dolu olduğu görüşündedir. Kütüphanenin bir kısmı kuzey sarayında, bir kısmı ise güneybatı sarayında yer almaktadır (Tekin, 2014). Ninova Sarayı Kütüphanesinde yer alan kaynaklar, resmi belgelerin yanı sıra, tıp, astronomi, mitoloji, büyücülük ve edebiyat konularını içeren kaynaklardan oluşmaktadır (Yıldız, 2003, s. 14).

\section{DEĞERLENDİRME VE SONUÇ}

Farklı yüzyıllarda insanlığa ve bilime hizmet etmiş Antik Çağ kütüphanelerinin kurulmuş oldukları coğrafi bölge, kültür, toplum ve bilimin de etkisiyle gerek kullanılan materyal türlerinde gerekse kütüphane kullanımlarında farklılıklar dikkat çekmektedir. Bunun en önemli örneklerinden olan Ninova Sarayı Kütüphanesinde kil tabletlerin kullanılıyor olması, papirüs ve parşömen kullanılan kütüphanelerin depolama alanlarında farklılıklara yol açmıştır. Efes Celcus, Pergamon ve İskenderiye Kütüphanelerinde papirüs ve parşömen kullanılan kaynakların rulolar haline duvarlar üzerinde bulunan nişlere yerleştirildiği belirlenmiştir.

Efes Celcus ve Pergamon Kütüphanelerinde bulundukları döneme ait çeşitli heykeller bulunmaktadır. Her ne kadar Pergamon bu konuda ilk olsa da Efes Celcus Kütüphanesi ile bu noktada benzer yönleri bulunmaktadır. Efes Celcus Kütüphanesinin bu noktada Pergamon Kütüphanesinden etkilendiği söylenebilir.

Efes Celcus kütüphanesinde yer alan iki duvar arasındaki koridorun kitapları korumak adına yapıldığı düşünülmektedir ve bu koridor sadece Efes Celcus kütüphanesinde bulunmaktadır. İskenderiye Kütüphanesinde kaynakların yangından kurtarılamaması, Efes Celsus Kütüphanesinde 
bulunan bu koridorun, kaynakları korumak adına yapıldığını düşündürmektedir. Ancak yine de yağmalar sırasında kütüphane ve içerisinde bulunan kaynaklar korunamamıştır.

Pergamon Kütüphanesi ve İskenderiye Kütüphanesinde bilginlerin toplandıkları, araştırma yaptıkları ve aynı zamanda fikir alışverişinde bulundukları salonlar mevcuttur. Bu salonlar, genel kaynakların bulunduğu alanlardan ve/veya salonlardan farklı bir yerde olup, günümüz kütüphane yapılarında bulunan "okuma salonu"na benzerinde yapı içerisine yerleştirilmiş odalardir.

Ninova Sarayı Kütüphanesi de Pergamon Kütüphanesi gibi iki odadan oluşmaktadır. Efes Celcus Kütüphanesi bu bakımdan diğer kütüphanelerden farklıdır. Efes Celcus Kütüphanesi iki katlı yapıdadır. İskenderiye ise iki ayrı kütüphane yapısından oluşmaktadır. Ayrıca İskenderiye Kütüphanesinde müze ve kütüphane iç içe bir yapıdadır.

Antik çağ kütüphanelerinin mimari yapısına yönelik hazırlanan çalışmalar ve bu konuda yapılan araştırmalar arkeolojik açıdan değerlendirilebildiği için elde edilen kaynaklar oldukça sınırlıdır. Aynı zamanda bu önemli kütüphanelerin farklı yüzyıllarda farklı coğrafyalarda, farklı kültürlerde ve farklı sosyal ve idari yapıya bağlı olarak oluşturulmaları mimari özelliklerini de etkilemiştir. Kütüphaneciliğin ilk temellerinin atılması açısından önemli olan bu kütüphaneler, insanlığa yüzyıllar boyunca hizmet etmiş ve ayakta kalmıştır.

Hakem Değerlendirmesi: Dış bağımsız.

Yazar Katkıları: Çalışma Konsepti/Tasarım- A.G., B.A.Ş.; Veri Toplama- A.G., B.A.Ş..; Veri Analizi/Yorumlama- A.G., B.A.Ş..; Yazı Taslağı- A.G., B.A.Ş.; İçeriğin Eleştirel İncelemesi- A.G., B.A.Ş.; Son Onay ve Sorumluluk- A.G., B.A.Ş. Çıkar Çatışması: Yazarlar çıkar çatışması bildirmemiştir.

Finansal Destek: Yazarlar bu çalışma için finansal destek almadığını beyan etmiştir.

Peer-review: Externally peer-reviewed.

Author Contributions: Conception/Design of Study- A.G., B.A.Ş..; Data Acquisition- A.G., B.A.Ş.; Data Analysis/ Interpretation-A.G., B.A.Ş.; Drafting Manuscript-A.G., B.A.Ş.; Critical Revision of Manuscript- A.G., B.A.Ş.; Final Approval and Accountability- A.G., B.A.Ş.

Conflict of Interest: The authors have no conflict of interest to declare.

Grant Support: The authors declared that this study has received no financial support.

\section{Kaynakça/References}

Ambrose, G., Harris, P. ve Stone, S. (2008). The visual dictionary of architecture. Ava Publishing: Switzerland. Blanck, H. (2000). Antikçağda kitap (Z. Aksu Yılmazer, Çev.). Dost Kitabevi Yayınları: Ankara.

Edwards, B. (2009). Libraries and learning recourse centers. Loutledge.

Fleming, J. ve Honour, H. (2016). Dünya sanat tarihi (H. Abacı, Çev.). Melisa Matbaacılık: İstanbul. 
Gül, Y. (1998). Antik kentler: Müzeler, defineler, antik kütüphaneler. Okullar Yayınevi: İzmir.

İskenderiye Kütüphanesi, bilime 1şık tutmayı sürdürüyor. (2021, 20 Mayıs). Erişim adresi: https://www.trthaber. com/haber/kultur-sanat/iskenderiye-kutuphanesi-bilime-isik-tutmayi-surduruyor-151571.html

Keseroğlu, H. (2010). Kütüphanenin değişen mimarisi. Dosya: Kütüphane Yapıları içinde (s. 46-54).

Keseroğlu, H. S. ve Demir, G. (2016). Antikçağda bilim ve kütüphane. Türk Kütüphaneciliği, 30(3), 365-397.

Kültür ve Turizm Bakanlığı. (2021). Erişim adresi: https://kulturportali.gov.tr/medya/fotograf/fotodokuman/3979/ efes-celsus-kutuphanesi

Macleod, R. (2006). Tarihte ve mitolojide İskenderiye. İskenderiye Kütüphanesi: Antik Dünya'nın Öğrenim Merkezi içinde (s. 13-35). Dost Yayınevi: Ankara.

Niş. (2021). Türk Dil Kurumu güncel Türkçe sözlük içinde. Erişim adresi: https://sozluk.gov.tr/

Sonay, P. G. (2019). Hellenistik ve Roma Dönemiınde küçük Asya>daki kütüphaneler (Yayımlanmamış yüksek lisans tezi). Kütahya Dumlupınar Üniversitesi, Kütahya.

Taşkın, Z. (2011). İlkçağ uygarlıklarında kitap ve kütüphane: Efes Celcus Kütüphanesi. Türk Kütüphaneciliği, 25(1), 86-96.

Tercan, A. (2010). Kütüphanenin mekânsal evrimi. Dosya: Kütüphane Yapıları içinde (s. 40-45).

Toplu, M. (2010). Kil tabletlerden elektronik yayınc1lı̆̆a kütüphanecilik felsefesinin gelişimi ve dönüşümü. Türk Kütüphaneciliği Dergisi, 24(4), 644-684.

Tunay, M. İ. (1970). Bergama Kütüphanesi. Türk Kütüphaneciliği, 19(2), 110-112.

Üreten, H. (2008). Antikçağ Anadolu'sunda bir kültür merkezi Pergamon- Kraliyet Kütüphanesi. Türk Kütüphaneciliği, 22(4), 435-450.

Yıldız, N. (2003). Kalıntılar ve edebi kaynaklar ışı̆̆ında antikçă̆ kütüphaneleri. İstanbul: Arkeoloji ve Sanat Yayınları. 
